\title{
Evaluating Rock Mass Properties of Vipingo Coral Limestone Quarry Based on a Modified Geological Strength Index (GSI) and State of Karstification
}

\author{
Joan Atieno Onyango ${ }^{1,2^{*}}$, Takashi Sasaoka ${ }^{1}$, Hideki Shimada ${ }^{1}$, \\ Akihiro Hamanaka1, Dyson Moses ${ }^{1}$, Dintwe Tumelo ${ }^{1}$ \\ ${ }^{1}$ Earth Resources Engineering Department, Kyushu University, Fukuoka, Japan \\ ${ }^{2}$ Mining, Materials and Petroleum Engineering Department, Jomo Kenyatta University of Agriculture and Technology, Nairobi, \\ Kenya \\ Email: *jaonyango@jkuat.ac.ke
}

How to cite this paper: Onyango, J.A., Sasaoka, T., Shimada, H., Hamanaka, A., Moses, D. and Tumelo, D. (2022) Evaluating Rock Mass Properties of Vipingo Coral Limestone Quarry Based on a Modified Geological Strength Index (GSI) and State of Karstification. Open Journal of Geology, $12,57-79$.

https://doi.org/10.4236/ojg.2022.121003

Received: December 7, 2021

Accepted: January 9, 2022

Published: January 12, 2022

Copyright $\odot 2022$ by author(s) and Scientific Research Publishing Inc. This work is licensed under the Creative Commons Attribution International License (CC BY 4.0).

http://creativecommons.org/licenses/by/4.0/

\begin{abstract}
The process of evaluating rock mass strength requires that major structural features such as joints that influence rock strength are considered. In carbonate rock masses, however, the strength of the rock mass is largely dependent on intact rock strength and structural features play a secondary role. Laboratory experiments on porous rock have shown that intact rock strength reduces with increasing porosity, which has a direct effect on the rock mass strength. Rock porosity has however not been well accounted for in rock mass characterization methods currently in use. This research applies the modified GSI method for carbonate rock masses which is based on a combination of GSI and total porosity. The main aim is to quantify the GSI with respect to rock porosity which is a direct indicator of the state of karstification, as an inherent feature that affects rock mass strength. An empirical equation is proposed whereby the GSI as observed in the field is modified by a natural $\log$ of the value of porosity, giving rise to a modified GSI (GSI $\left.{ }_{\mathrm{m}}\right)$. The $\mathrm{GSI}_{\mathrm{m}}$ together with laboratory properties of rock is used to determine the properties of Vipingo coral limestone from RocLab software. A deterministic parametric slope stability analysis is done using the finite element software Phase 2 with the rock mass properties as input parameters. The analysis results point to a direct dependence of the slope stability on slope angle, slope height and rock mass strength of the lithological unit. The graphs make a useful design guide for slopes engineered in this type of rock mass.
\end{abstract}




\section{Keywords}

Carbonates, Karstification, Porosity, Rock Mass Strength, Slope Stability, Weak Rock

\section{Introduction}

Determination of rock mass mechanical properties is crucial for geoengineering works in civil applications such as tunnels, slopes, foundations and mining operations, both surface and underground. The originally developed rock mass classification systems of RMR and Q-system served the purpose quite well in conjunction with the Hoek-Brown failure criterion. However, it, later on, became obvious that the systems were not adequately applicable to weak rocks as a result of a breakdown in the relationship between RMR and Hoek-Brown constants for severely fractured and weak rocks. Besides, the RMR system and Q-system relied on RQD which is difficult to obtain for weak rock masses due to very poor core recovery. The Geological strength index (GSI) developed by Evert Hoek [1] became a suitable alternative classification system based on geological observation of rock mass properties. After its development, a lot more research studies and modifications have been conducted by different researchers on various aspects of the GSI system to take care of weak, jointed, and heterogenous rock masses [2].

In order to achieve the basic objective of the GSI system which is to aid in estimating rock mass properties, Hoek [3] linked the constants of the Hoek-Brown failure criterion with rock mass quality from the basic GSI chart. There arose a need to accommodate the weak schist rock masses of Athens which happens to be foliated/laminated/sheared into the GSI system. Hoek, Marinos and Benissi [4] therefore extended the GSI chart by adding a category that represents thinly laminated, foliated and structurally sheared weak rocks. All through its inception up until 1998, the GSI was estimated qualitatively based on geological visual observations hence there would be a wide variation in GSI values for a particular rock mass depending on the professional expertise of the data collector. Sonmez and Ulusay [5] tried to transcend these challenges by developing a quantitative numerical basis for estimating the GSI values and well quantities for rock mass properties. Another category named intact/massive rock was added to the GSI chart by Marinos and Hoek [6] when they worked on jointed rock masses surrounding tunnels in Greece. In this case, joint characteristics were added to the GSI chart to complement lithology, structure and surface conditions of rock mass discontinuities. Further quantification of the GSI was done through the introduction of block volume $\left(V_{b}\right)$ and joint condition $\left(J_{c}\right)$ factor in the structure domain of the GSI by Cai, Kaiser, Uno and Tasaka [7]. The introduction of these parameters improved the simplicity of the GSI chart as well as reduced dependency on professional expertise in collecting field GSI data. Further develop- 
ments were done by Hoek and Marinos including incorporating weak, heterogenous rock masses and lithological variability of the rock mass [8]. Further improvements involved calibration of the GSI chart such that the X-axis represented the surface quality while the $\mathrm{Y}$-axis represented block interlocking and structure domains of the rock mass [9].

Despite the developments made in GSI to accommodate weak rock masses, some other classes of weak rocks are still not well represented in the current GSI charts. Discontinuities in rock masses have been well researched as a major factor affecting rock mass strength. The other factor that influences rock mass strength is the rock fabric. Laboratory experiments on porous carbonate and evaporite rocks have proven that rock porosity has a direct bearing on rock strength. This factor has not been considered in GSI classification of rocks. In a bid to factor in the mechanical and hydraulic characteristics of carbonate rock mass and especially karstic rocks, Špago and Jovanovski [10] proposed a combination of GSI value with the state of karstification while working on the carbonate complexes at "Salakovac", "Grabovica" and "Sveta Petka" dam sites. The classification system separated carbonate rock complexes into two groups; 1) those without beddings or foliations and 2) those with distinct bedding planes. According to the proposed method, the GSI value obtained from the modified GSI chart is combined with the rock porosity to classify the rock mass based on the degree of karstification. Hu, Wen, Zheng and Wang [11] tried to factor in the effects of rock porosity to the Hoek-Brown criterion for determining rock mass properties by using the relationship between intact rock and porosity to replace the value of GSI in the empirical equations.

In this study, the method proposed by Špago and Jovanovski [10] is employed to characterize a coralline rock mass by taking into consideration the state of karstification. The classification method however doesn't assign a specific value to the GSI class where a rock mass has been placed with respect to the total porosity. The aim of this work is therefore to quantify this classification scheme whereby the GSI as observed in the field is modified with respect to the rock porosity which is a direct indicator of the state of karstification in the rock mass. The relationship is expected to take care of the strength reduction characteristic of porosity on the rock mass strength as well as the weathering effects arising from the porous nature of the rocks. The modified GSI in conjunction with intact rock properties is used to obtain rock mass parameters from the already existing Hoek-Brown criterion, after which a parametric slope stability analysis is done.

\section{Theoretical Background of the Hoek-Brown Criterion}

Hoek-Brown criterion was introduced to help in providing input parameters for the design of underground excavations, starting from intact rock properties then introducing factors that affect these properties on the basis of joint characteristics in the rock mass [12]. The criterion was first linked to Rock Mass Rating 
(RMR) but was not adequately relating the failure criterion to field observations for weak rocks so the GSI was proposed in 1994 by Hoek and Karzulovic [13]. The original Hoek-Brown criterion was defined by Equation (1) as follows;

$$
\sigma_{1}^{\prime}=\sigma_{3}^{\prime}+\sigma_{c i}\left(m_{i} \frac{\sigma_{3}^{\prime}}{\sigma_{c i}}+s\right)^{0.5}
$$

where $\sigma_{1}^{\prime}$ and $\sigma_{3}^{\prime}$ are the major and minor effective principal stresses at failure, $\sigma_{c i}$ is the uniaxial compressive strength of the intact rock material, $m$ and $s$ are material constants, where $s=1$ for intact rock.

The generalized Hoek-Brown criterion was later introduced, replacing the square root by a variable a so as to better account for extremely poor quality rock masses such that even under very low normal stresses, the curvature of the failure envelope can be adjusted [1]. It is expressed as shown in Equation (2);

$$
\sigma_{1}^{\prime}=\sigma_{3}^{\prime}+\sigma_{c i}\left(m_{b} \frac{\sigma_{3}^{\prime}}{\sigma_{c i}}+s\right)^{a}
$$

where $m_{b}$ is a reduced value of the material constant $m_{i}$ and is given by Equation (3);

$$
m_{b}=m_{i} \exp \left(\frac{\mathrm{GSI}-100}{28-14 D}\right)
$$

$m_{i}$ is intact rock material constant obtained from the estimates tabled in Hoek \& Brown [14] when experimental values are not achievable. In the 2002-edition of the Hoek-Brown criterion, the disturbance factor $D$ was introduced and incorporated into the formulas for the constants a and s [12] as illustrated by Equation (4) and Equation (5).

$$
\begin{gathered}
a=\frac{1}{2}+\frac{1}{6}\left(\mathrm{e}^{-\mathrm{GSI} / 15}-\mathrm{e}^{-20 / 3}\right) \\
s=\exp \left(\frac{\mathrm{GSI}-100}{9-3 D}\right)
\end{gathered}
$$

The uniaxial compressive strength is obtained by setting $\sigma_{3}^{\prime}=0$ in Equation (2) thus giving rise to Equation (6):

$$
\sigma_{c m}=\sigma_{c i} \cdot s^{a}
$$

The tensile strength is given by Evert Hoek [15] as shown in Equation (7) below:

$$
\sigma_{t m}=-\frac{s \sigma_{c i}}{m_{b}}
$$

Other empirical equations were developed by Aydan, Akagi and Kawamoto [16] [17] to express shear strength parameters of the rock mass in terms of the rock mass compressive strength. The cohesion $c_{m}$, friction angle $\phi_{m}$ and the Poissons's ratio $v_{m}$ for the rock mass are obtained by the following Equations (8)-(10). 


$$
\begin{gathered}
\phi_{m}=20 \sigma_{c m}^{0.25} \\
c_{m}=\frac{\sigma_{c m}}{2} \frac{1-\sin \phi_{m}}{\cos \phi_{m}} \\
v_{m}=0.25\left(1+\mathrm{e}^{-\sigma_{c m} / 4}\right)
\end{gathered}
$$

Hoek and Diederichs [18] then proposed Equation (11) for estimating rock mass modulus from the intact rock modulus;

$$
E_{m}(\mathrm{GPa})=E_{i}\left\{0.02+\frac{1-D / 2}{1+\exp [(60+15 D-\mathrm{GSI}) / 11]}\right\}
$$

where $E_{i}$ is the intact rock deformation modulus and $D$ is the disturbance factor.

\section{Modified GSI System for Carbonate Rocks}

\section{The GSI Charts for Carbonates}

The modified GSI method classifies carbonate rock complexes into two classes depending on presence or absence of beddings/foliations. In the case of rock mass with no beddings/foliations, the GSI values are determined based on two fundamental geological parameters i.e. the structure (blockiness) of the rock mass and the surface condition of the discontinuities indicated by joint roughness and alteration. The resulting GSI chart is in Figure 1. For rock mass with distinct bedding planes, the GSI value is based on the thickness of the strata and surface condition of the discontinuities, as illustrated in Figure 2. Besides the description of the rock mass structure, the classification system is complemented by the uniaxial compressive strength or point load index values of the intact rock and discontinuity spacing.

Five classes of rock mass structure presented in the charts are as outlined below:

- Very good-Very rough, fresh unweathered surfaces.

- Good-Rough, slightly weathered surfaces.

- Fair-Smooth, moderately weathered and altered surfaces.

- Poor-Very smooth or highly weathered surfaces, occasionally slickensided with compact coatings or fillings with angular fragments.

- Very poor-Very smooth slickensided or highly weathered surfaces with soft clay coatings or filings.

- N/A-refers to cases which are not possible in practice.

The GSI values were then combined with state of karstification which is determined by the level of surface decomposition or solubleness as illustrated by Bell [19] giving rise to the following five classes:

- Class V-not typical for soluble rocks and in carbonate rocks, the "terra rosa" (red soil made by decomposition of carbonate rocks) corresponds.

- Class IV-very soluble rock, more than $50 \%$ of rock can be soluble and taken from massive and in the discontinuities can be found small amount of residuum. 


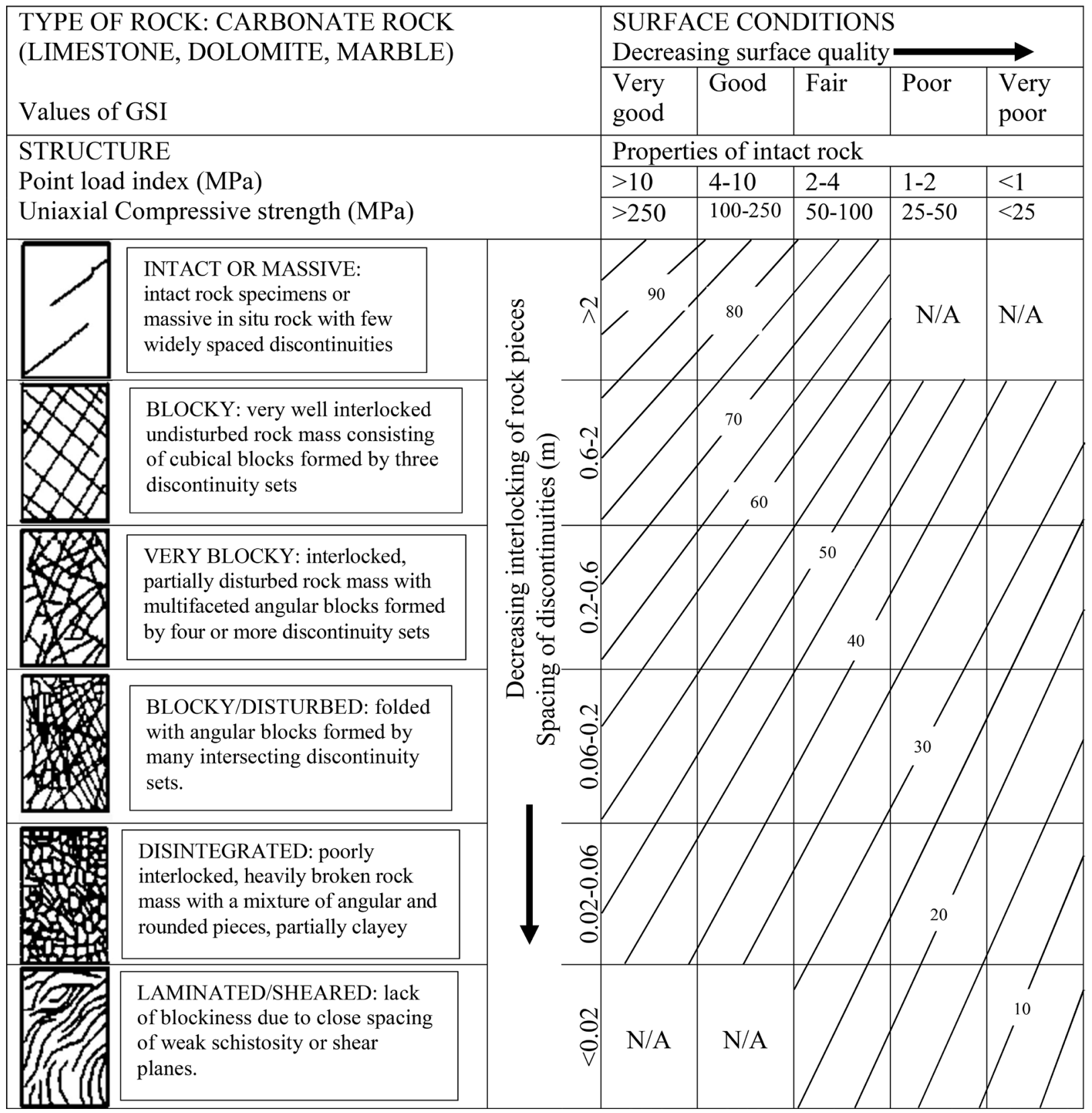

Figure 1. Possible physical models for carbonate rock masses without beddings/foliations defined by the modified GSI classification [10].

- Class III-medium decomposed rock, near $50 \%$ of rock can be soluble, but rock's structure stays untouched.

- Class II-poorly decomposed rock, with opened discontinuities, and rock mass itself is poorly soluble under discontinuities.

- Class I-fresh indissoluble rock with compressed discontinuities.

The five classes of carbonate rock mass combined with rock porosity results in classification of carbonated rock formation are shown in Figure 3. There is a total of 25 combinations but some are not feasible (denoted by N/A) while others are rarely possible (R/A) hence 13 main possible classifications are tenable for 


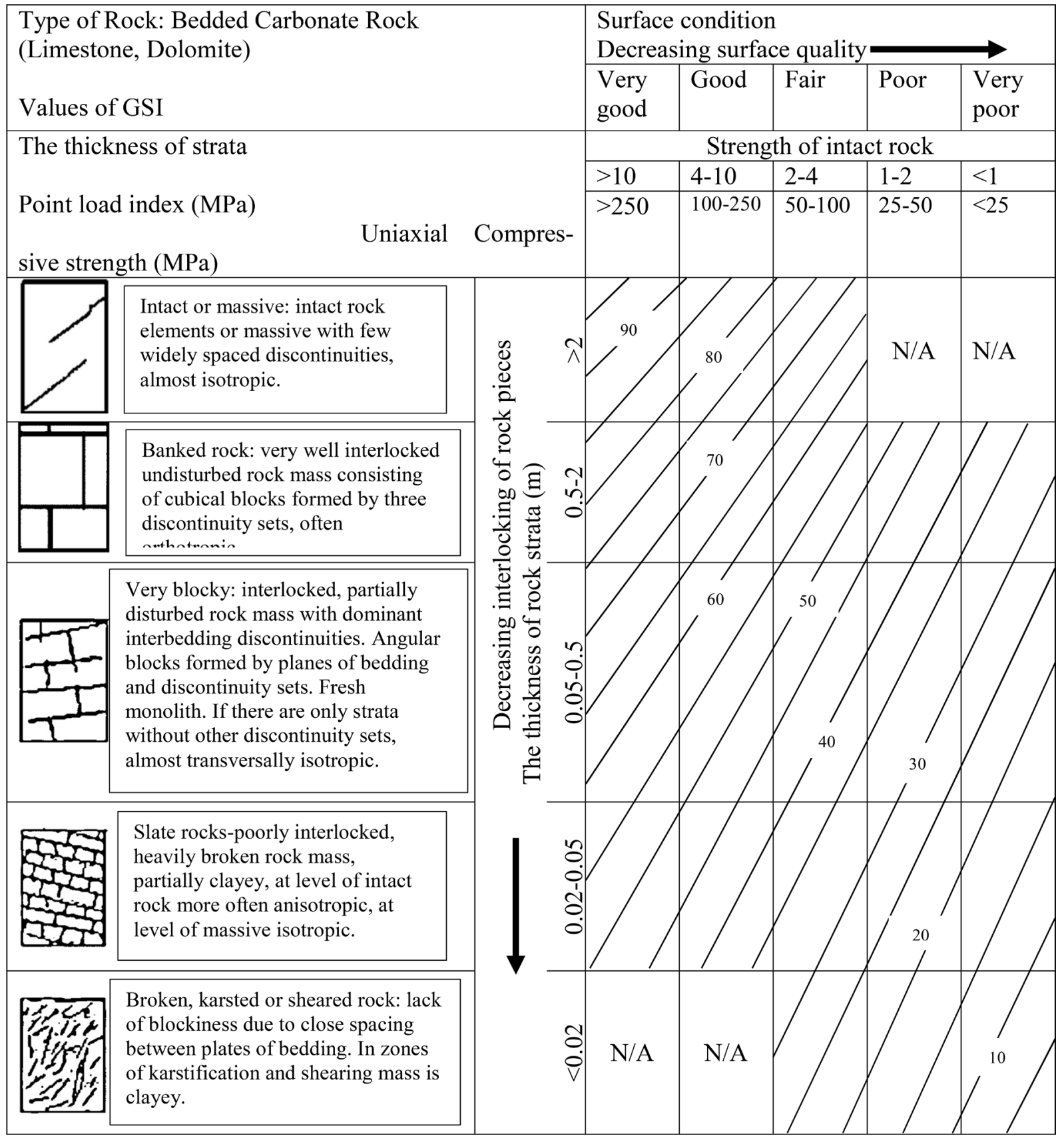

Figure 2. Possible physical models for carbonate rock masses defined by modified GSI classification for rock mass with distinct bedding [10].

porous carbonate rock.

The classification system shows a decrease of GSI with increasing rock porosity, a phenomenon that is congruent with laboratory experiments which have shown a direct relationship of decreasing intact rock strength with increasing porosity. In this work, the relationship between GSI and porosity is quantified such that the GSI for porous rock mass is modified with respect to percent porosity. The Hoek-Brown parameters, which are the basis for empirical equations for determining rock mass properties, are usually calculated using GSI and so a 
modification of the GSI in relation to porosity will definitely account for rock mass strength degradation due to karstification.

To obtain a quantitative relationship between GSI and rock porosity, the range of practically possible values in Figure 3 were plotted to obtain the graph in Figure 4. The graph has a characteristic logarithmic relationship expressed as $y=b-a \ln (x)$. The correlation coefficient is quite low meaning that the equation can only be realistically applicable within specific ranges of porosity. The

\begin{tabular}{|c|c|c|c|c|c|c|}
\hline \multicolumn{7}{|c|}{ Classes by total porosity of carbonate rock mass } \\
\hline \multirow{3}{*}{ 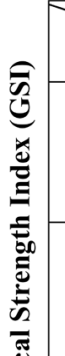 } & GSI $n(\%)$ & $\begin{array}{c}\mathrm{A} \\
\mathrm{n}<2 \%\end{array}$ & $\begin{array}{c}B \\
n=2-5 \%\end{array}$ & $\begin{array}{c}C \\
n=5-10 \%\end{array}$ & $\begin{array}{c}D \\
n=10-20 \%\end{array}$ & $\begin{array}{c}E \\
n>20 \%\end{array}$ \\
\hline & $\begin{array}{c}\mathrm{I} \\
\mathrm{GSSI}=81-100\end{array}$ & A-I & B-I & $\mathrm{R} / \mathrm{A}$ & N/A & N/A \\
\hline & $\begin{array}{c}\text { II } \\
\text { GSI }=61-80\end{array}$ & A-II & B-II & C-II & $\mathrm{R} / \mathrm{A}$ & N/A \\
\hline 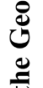 & $\begin{array}{c}\text { III } \\
\text { GSI }=41-60\end{array}$ & $\mathrm{R} / \mathrm{A}$ & B-III & C-III & D-III & $\mathrm{R} / \mathrm{A}$ \\
\hline 兑 & $\begin{array}{c}\text { IV } \\
\text { GSI }=21-40\end{array}$ & N/A & $\mathrm{R} / \mathrm{A}$ & C-IV & D-IV & E-IV \\
\hline Uू & $\begin{array}{c}\mathrm{V} \\
\mathrm{GSI}=10-2\end{array}$ & N/A & N/A & $\mathrm{R} / \mathrm{A}$ & $D-V$ & E-V \\
\hline
\end{tabular}

Figure 3. Proposed system of combination of rock's quality and state of karstification [10].

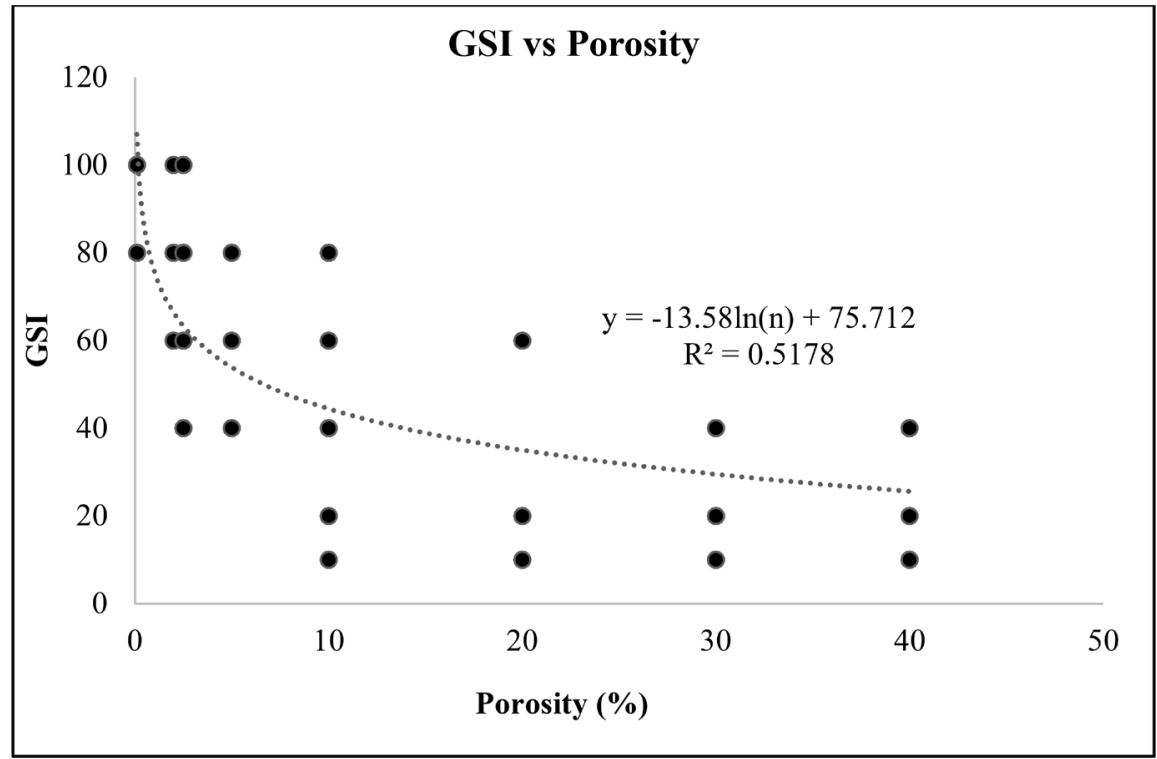

Figure 4. Relationship between GSI and rock porosity (n). 
GSI decreases sharply with increasing porosity as can be seen in the steep slope of the graph for porosity ranges $0 \%-10 \%$, after which the slope becomes gentle with further increase in porosity. The reason for this is similar to the explanation given by $\mathrm{Hu}$, Wen, Zheng and Wang [11] on why rock strength decreases with increasing porosity, being a result of changes in binding forces between rock grains. As the porosity increases, the rock strength reduces due to increasing pore spaces which likely join up with discontinuities in the rock mass and reduce the blockiness of the rock mass hence the steep slope of the first part of the graph. With further increase in porosity, the pores end up interconnecting leading to a disintegrated rock mass.

\section{The Case of Vipingo Coral Limestone Quarry}

\subsection{Geology of Vipingo Area}

Vipingo area is situated in Kilifi area along the Coastal Plain of Kenya which lies along the Indian Ocean sea shore and reaches $3-8 \mathrm{~km}$ inland, with elevations mostly less than $33 \mathrm{~m}$ above sea level and up to $100 \mathrm{~m}$ thick. It is part of the larger coralline limestone deposit of Pleistocene age that spans the Indian Ocean coastal line from Tanzania in the south to Malindi (Kenya) in the North.

The total carbonates content is about $95 \%$, the limestone being characterized by high textural porosities manifesting in density values as low as $0.5 \mathrm{~g} / \mathrm{cm}^{3}$ for in situ average of around $1.5 \mathrm{~g} / \mathrm{cm}^{3}$ which also allows high free silica content. Apart from structurally entrapped moderate to high silica values being present due to normal reef building mechanisms, aeolian free sand exacerbates the problem and generally tends to increase the variability in grade of the limestone. In well-defined areas the coralline body has been subjected to intensive karstifications and resultant distinct voiding or caving. It also makes for a free silica source with two free silica sources identified: 1) free silica entrapped inside the pores and voids of the coral reefs and 2) the red ferruginous sandy sediment which is located mainly on the most upper 2 meters of the deposits. No distinct bedding or foliation is visible in this rock formation.

The quarry mines coral limestone for cement production but is in the process of implementing a rehabilitation plan for the mined-out sections of the quarry. An understanding of the properties of the geotechnical properties of the rock mass is important for guiding decisions on design of the final pit slopes to guarantee long-term safety as well as safety of the adjacent infrastructure. Physical-mechanical properties of coral limestone rock obtained from laboratory experiments by the author are given in Table 1 .

ISRM's classification of rocks based on rocks based on intact rock strengths as shown in Figure 5 categorizes the rock as weak since the average UCS value is 16.41 MPa.

According to Martin and Stacey [21], from cases histories, the operational strength of rock masses in this category is always less than the laboratory strength, even below $50 \%$ for mudrocks, the cause notwithstanding. It is therefore 
Table 1. Intact rock properties.

\begin{tabular}{cccc}
\hline Property & Units & Value & Mean \\
\hline Dry density & $\left(\mathrm{kg} / \mathrm{m}^{3}\right)$ & $1893-2514$ & 2199 \\
Saturated density & $\left(\mathrm{kg} / \mathrm{m}^{3}\right)$ & $1906-2493$ & 2255 \\
Porosity & $\%$ & $1.56-17.20$ & 8.97 \\
UCS (dry) & $\mathrm{MPa}$ & $5.24-36.06$ & 16.41 \\
Tensile strength & $\mathrm{MPa}$ & $1.06-2.24$ & 1.61 \\
P-Wave velocity & $(\mathrm{km} / \mathrm{s})$ & $4.23-5.50$ & 4.86 \\
S-Wave velocity & $(\mathrm{km} / \mathrm{s})$ & $2.00-2.74$ & 2.29 \\
Elastic Modulus & $\mathrm{GPa}$ & $21.08-45.73$ & 31.62 \\
Shear Modulus & $\mathrm{GPa}$ & $7.56-17.13$ & 11.68 \\
Bulk Modulus & $\mathrm{GPa}$ & $1.48-5.04$ & 3.09 \\
P-Wave Modulus & $\mathrm{GPa}$ & $36.18-75.79$ & 52.32
\end{tabular}

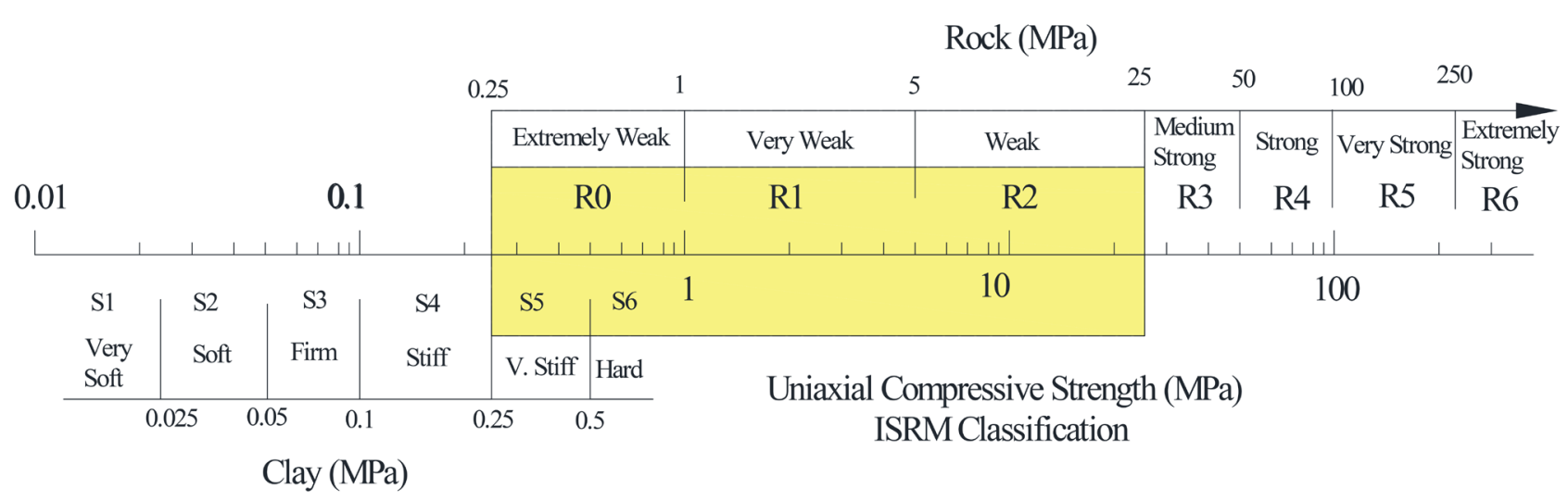

Figure 5. ISRM classification of rocks based on uniaxial compressive strength [20].

recommended that mechanical analyses involving rock masses in weak rocks should make use of rock mass mechanical properties instead of intact properties.

\subsection{GSI Classification of Various Lithological Units}

The carbonate coral limestone rock formation has the following geological characteristics:

- Regions of low strength and porous intact rock, overlain with top soil or in some cases weathered rock (rock whose pores and fissures are filled with soil). This top soil/weathered rock varies in thickness from $<0.5-3 \mathrm{~m}$ deep.

- The rock grade increases with depth i.e. less soil infilling though porosity and occurrence of karst features is random.

- Coral sands also exist in the southern region of the quarry, up to about $4 \mathrm{~m}$ thick layer.

- Karstification is evident in distinctly developed karst features such as voids, and cavities, and dissolution fissures. 
Eight geological units were studied and classified as illustrated in Figures 6-13. The rock mass classification is summarized in Table 2.

A graph plotted of GSI against porosity based on Table 2 is given in Figure 14 below.

The equation of the graph of GSI against porosity (Equation (12a) has a logarithmic relation of the form $y=a \ln (x)+b$ with a correlation coefficient of 0.92 .

$$
\mathrm{GSI}=-14.19 \ln (n)+52.817,
$$

where $\mathrm{n}$ is the rock porosity.

Taking whole number values, the equation relating GSI and porosity for the
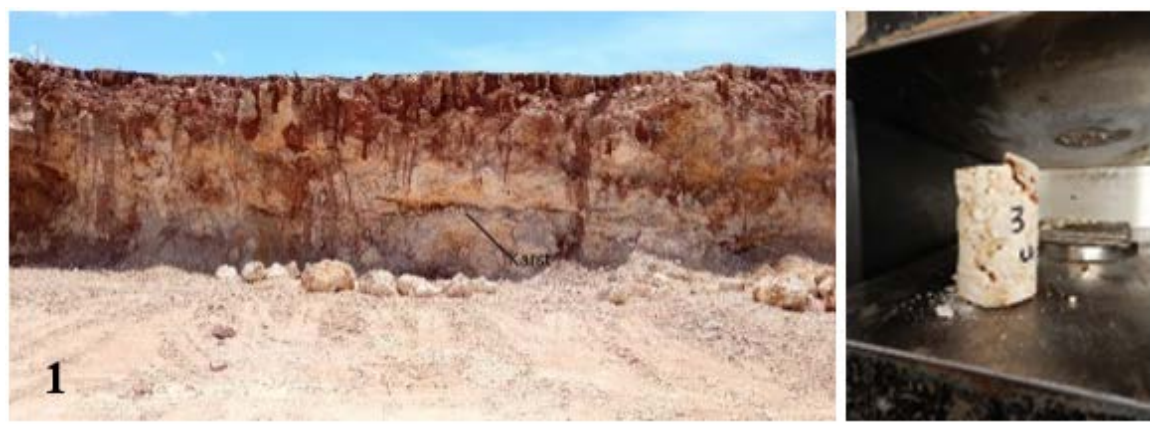

Figure 6. Litho1: Rock mass is poorly interlocked, pores and fissures filled with soil. UCS $=17.43 \mathrm{MPa}, n=11.82 \%$, GSI $=19$.

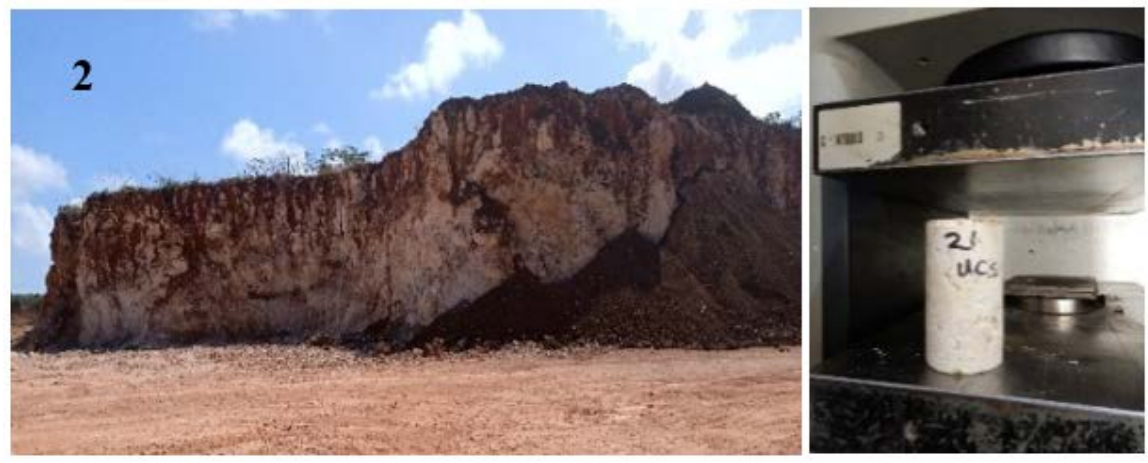

Figure 7. Litho2: Rock mass is blocky. UCS $=17.64 \mathrm{MPa}, n=1.56 \%, \mathrm{GSI}=2$.
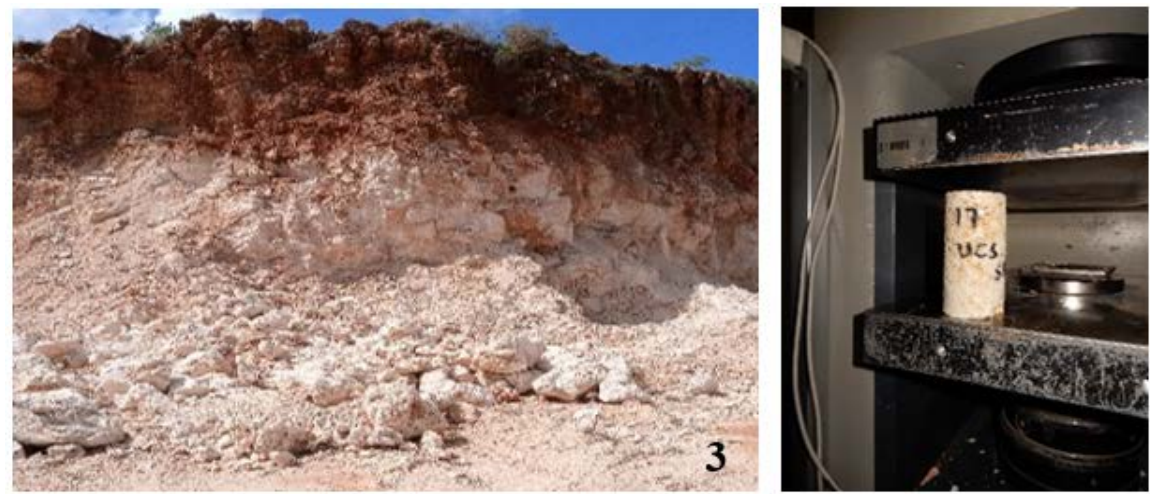

Figure 8. Litho3: Disintegrated high-grade rock is overlain with a layer of weathered rock/top soil. UCS $=5.24 \mathrm{MPa}, n=10.7 \%, \mathrm{GSI}=17$. 

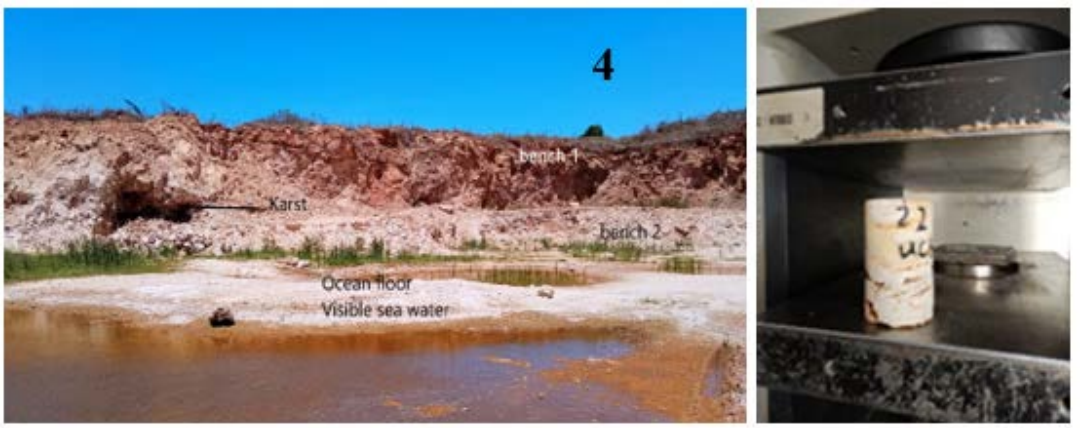

Figure 9. Litho4: Heavily broken rock, lack of blockiness, clayey. UCS = 5.7 MPa, $n=13.15 \%$, GSI $=14$.
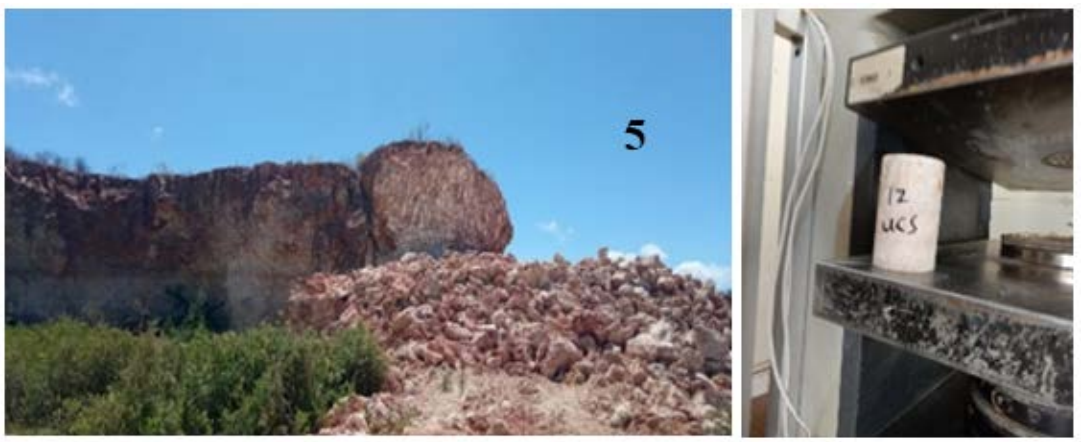

Figure 10. Litho5: Rock mass is blocky. UCS $=36.06 \mathrm{MPa}, n=5.4 \%$, GSI $=30$.
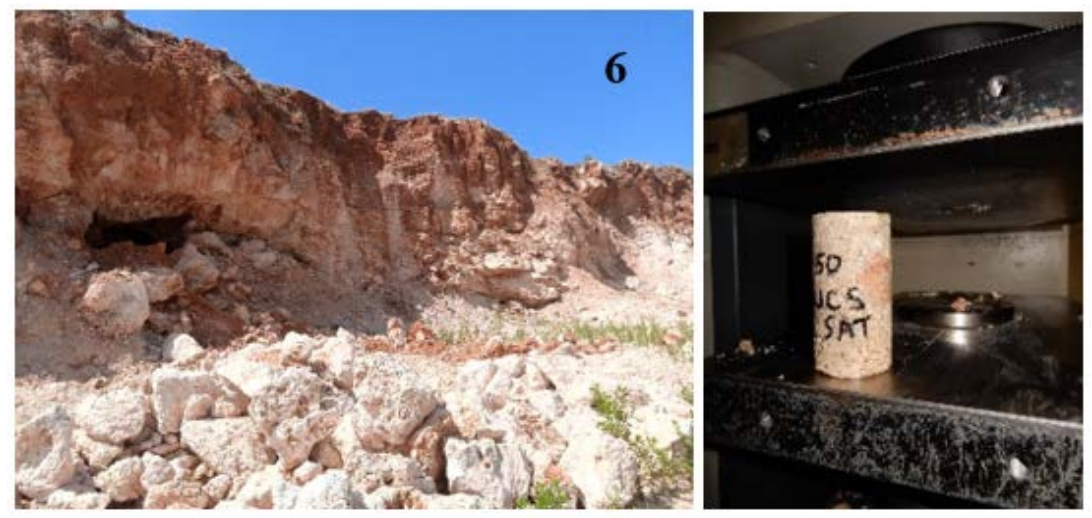

Figure 11. Litho6: Brocken rock, clayey, UCS $=12.59 \mathrm{MPa}, \mathrm{GSI}=18, n=15.25 \%$.
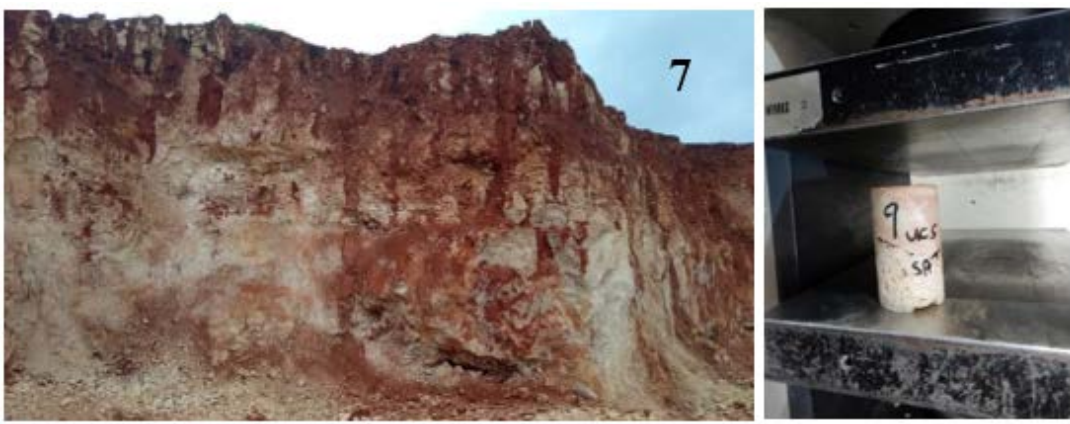

Figure 12. Litho7: Blocky rock structure, evident karstification with traces of soil in the rock mass. UCS $=19.47 \mathrm{MPa}, n=8.43 \%$, GSI $=24$. 

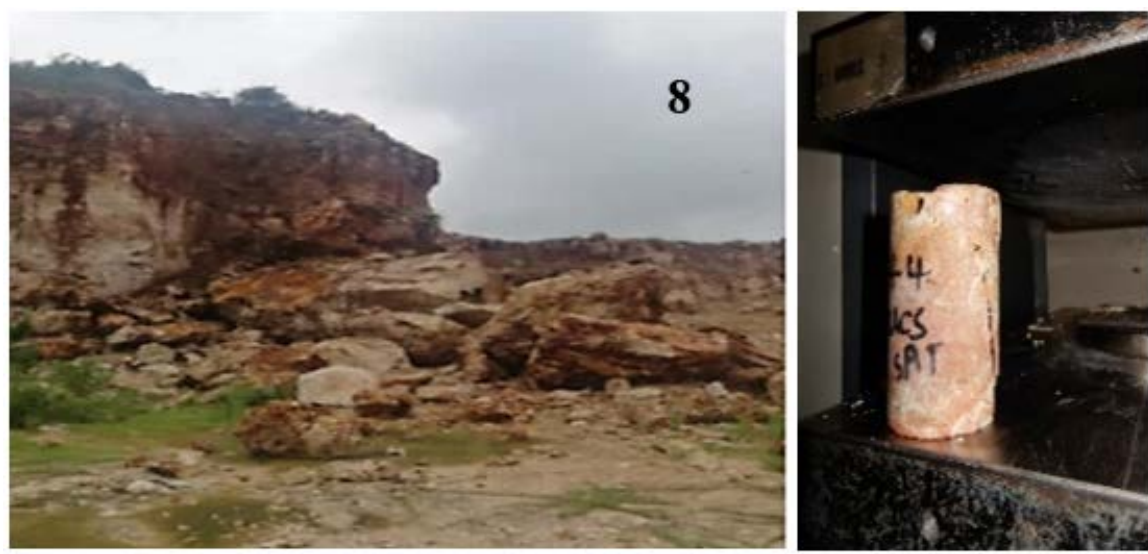

Figure 13. Litho8: Rock mass is blocky. UCS $=23.49, n=5.31 \%$, GSI $=28$.

Table 2. Rock mass classification of Vipingo limestone.

\begin{tabular}{ccccc}
\hline Litho unit & CLASS & GSI & UCS (MPa) & Porosity $(\boldsymbol{n}) \%$ \\
\hline 1 & D-V & 19 & 17.43 & 11.82 \\
2 & N/A & 23 & 17.64 & 1.56 \\
3 & D-V & 17 & 5.24 & 10.70 \\
4 & D-V & 14 & 5.70 & 13.15 \\
5 & C-IV & 30 & 36.06 & 5.40 \\
6 & D-V & 18 & 12.59 & 15.25 \\
7 & C-IV & 24 & 19.47 & 8.43 \\
8 & C-IV & 28 & 23.49 & 5.31
\end{tabular}

Description of the rock mass classes (from Figure 3). C-IV: GSI $=21-40$, porosity $=5 \%$ $10 \%$. Very soluble rock, more than $50 \%$ of rock can be soluble and taken from massive and in the discontinuities can be found small amount of residuum. D-V: GSI $=10-20$, porosity $=10 \%-20 \%$. Not typical for soluble rocks and in carbonate rocks, the "terra rosa" (red soil made by decomposition of carbonate rocks) corresponds.

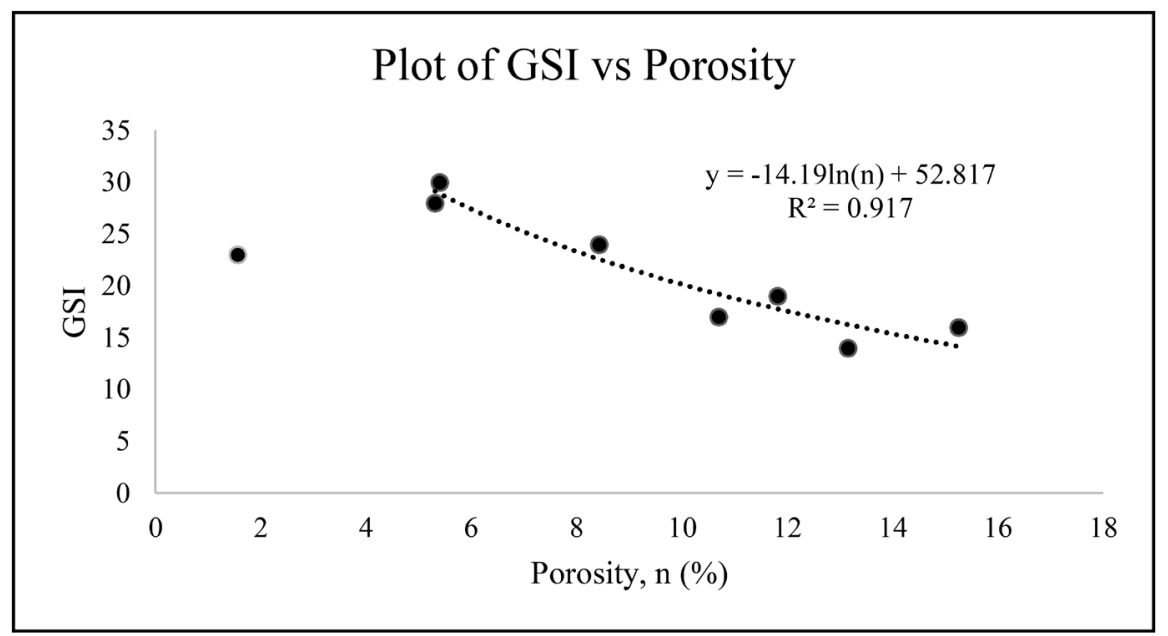

Figure 14. GSI vs Porosity plot for coral limestone from Vipingo quarry. 
coral limestone is given by Equation (12b);

$$
\mathrm{GSI}=53-14 \ln (n), 5 \% \leq n \leq 15 \%
$$

where 53 is given a physical meaning of the GSI when $n=1 \%$ and 14 being a fitting value.

Equation (12) is valid for a porosity range of $5 \% \sim 15 \%$. In a bid to express it in terms of GSI only and make it applicable to all states of karstification, it is further simplified based on the sequence of values yielded by the equation. The value 53 is therefore replaced by GSI value recorded from the field and the final equation for GSI of porous rock mass is given by Equation (13) as;

$$
\mathrm{GSI}_{\mathrm{m}}=\mathrm{GSI}-0.6 \ln (n) \text {, }
$$

where GSI $_{\mathrm{m}}$ is the modified GSI and $\mathrm{n}$ is porosity (\%)

As recommended by Vassilis and Carter [22], geological processes of tectonism, weathering and/or alteration which bring about changes that significantly affect the GSI can be analyzed and key parameter characteristics modified accordingly. On this basis, Equation (13) gives a more logical way of incorporating the strength reduction effect of rock porosity on the rock mass, thus taking care of karstification and weathering effects in rock mass classification for carbonate rock masses.

The classification system that combines GSI and state of karstification (herein represented by the value of porosity) in Figure 3 is thus quantified using Equation (13). Consequently, the GSI values in Table 2 are modified with respect to rock porosity to generate the modified GSI $\left(\mathrm{GSI}_{\mathrm{m}}\right)$ values as given in Table 3 .

\subsubsection{The Rock Mass Properties}

The rock mass properties were determined from RocLab software based on Hoek-Brown criterion, with $\mathrm{GSI}_{\mathrm{m}}$ and intact rock properties as input parameters. The intact properties were obtained from a series of laboratory tests that are based on ASTM standards. The value of mi could not be obtained experimentally and so was obtained from the table presented in Hoek and Brown [14]. The rock mass properties are presented in Table 4.

Table 3. Modified GSI values.

\begin{tabular}{ccccc}
\hline Litho unit & CLASS & GSI & Porosity $(\boldsymbol{n}) \%$ & GSI $_{\mathrm{m}}$ \\
\hline 1 & D-V & 19 & 11.82 & 18 \\
2 & N/A & 23 & 1.56 & 23 \\
3 & D-V & 17 & 10.70 & 16 \\
4 & D-V & 14 & 13.15 & 12 \\
5 & C-IV & 30 & 5.40 & 29 \\
6 & D-V & 18 & 15.25 & 17 \\
7 & C-IV & 24 & 8.43 & 22 \\
8 & C-IV & 28 & 5.31 & 27 \\
\hline
\end{tabular}


Comparing intact rock and rock mass properties in Table 4, the rock mass strength is way lower than intact rock strength by orders of magnitude. The UCS for the rock mass for instance, is about $0.2 \%$ of the intact rock strength. Martin and Stacey [21] have recorded the observation of operational slope strength in weak rock masses being way lower than laboratory rock strength. In the case of carbonate rock, it is attributed to the presence of dissolution karst features formed by water seeping through the porous rock mass and also macromechanical processes of grain crushing and pore collapse. The laboratory specimen has pores and small cavities developed from interconnected pores while the rock mass is further complicated by reduced blockiness, dissolution fissures and general weathering. A host of factors contribute to severe reduction of the rock mass strength.

\subsubsection{Failure Envelope}

The failure envelopes give a visual impression of the strength limits of the rock mass. Mohr-Coulomb and Generalized Hoek-Brown failure envelopes were plotted for this rock mass using a $G S I_{m}$ of 20 . Figure 15 shows the principal stress envelope while Figure 16 is the shear strength envelope. The uniaxial compressive strength of the rock mass $\sigma_{c m}$ is given by Equation (6). Failure initiates at the boundary of an excavation when $\sigma_{c m}$ is exceeded by the stress induced on that boundary. The failure propagates from this initiation point into a

Table 4. Rock mass properties.

\begin{tabular}{|c|c|c|c|c|c|c|c|c|c|c|c|}
\hline Parameters & & Units & 1 & 2 & 3 & 4 & 5 & 6 & 7 & 8 & Mean \\
\hline \multirow{9}{*}{$\begin{array}{c}\text { Hoek-Brown } \\
\text { classification } \\
\text { and intact } \\
\text { rock } \\
\text { properties }\end{array}$} & $\sigma_{c i}$ & $\mathrm{MPa}$ & 17.43 & 17.64 & 5.24 & 5.7 & 36.06 & 12.59 & 19.47 & 23.49 & 17.2 \\
\hline & $E_{i}$ & $\mathrm{GPa}$ & 24.45 & 44.53 & 22.31 & 21.08 & 45.73 & 41.54 & 26.2 & 35.91 & 32.72 \\
\hline & GSI & & 19 & 23 & 17 & 14 & 30 & 18 & 24 & 28 & 21 \\
\hline & $\mathrm{GSI}_{\mathrm{m}}$ & & 18 & 23 & 16 & 12 & 29 & 17 & 22 & 27 & 20 \\
\hline & $m_{i}$ & & 9 & 9 & 9 & 9 & 9 & 9 & 9 & 9 & 9 \\
\hline & $D$ & & 0.7 & 0.7 & 0.7 & 0.7 & 0.7 & 0.7 & 0.7 & 0.7 & 0.7 \\
\hline & $n$ & $\%$ & 11.82 & 1.56 & 10.7 & 13.15 & 5.4 & 5.31 & 15.25 & 8.43 & 8.95 \\
\hline & $v_{i}$ & & 0.34 & 0.36 & 0.35 & 0.39 & 0.33 & 0.35 & 0.35 & 0.4 & 0.36 \\
\hline & $\gamma$ & $\mathrm{MN} / \mathrm{m}^{3}$ & 0.0207 & 0.0251 & 0.0195 & 0.0189 & 0.0228 & 0.0214 & 0.0233 & 0.024 & 0.022 \\
\hline \multirow{3}{*}{$\begin{array}{c}\text { Hoek-Brown } \\
\text { criterion }\end{array}$} & $a$ & & 0.55 & 0.536 & 0.557 & 0.575 & 0.524 & 0.553 & 0.538 & 0.527 & 0.544 \\
\hline & $s$ & & $6.90 \mathrm{E}-06$ & $1.42 \mathrm{E}-05$ & $5.16 \mathrm{E}-06$ & $2.89 \mathrm{E}-06$ & $3.40 \mathrm{E}-05$ & $5.97 \mathrm{E}-06$ & $1.23 \mathrm{E}-05$ & $2.54 \mathrm{E}-05$ & $9.22 \mathrm{E}-06$ \\
\hline & $m_{b}$ & & 0.099 & 0.131 & 0.089 & 0.072 & 0.182 & 0.094 & 0.124 & 0.163 & 0.111 \\
\hline \multirow{2}{*}{$\begin{array}{l}\text { Mohr-Coulo } \\
\text { mb criterion }\end{array}$} & $\varphi^{\prime}$ & deg & 24.83 & 27 & 17.06 & 15.22 & 36.48 & 21.95 & 27.52 & 31.79 & 25.75 \\
\hline & $c^{\prime}$ & $\mathrm{MPa}$ & 0.039 & 0.056 & 0.021 & 0.017 & 0.09 & 0.033 & 0.053 & 0.072 & 0.048 \\
\hline Rock Mass & $\sigma_{c m}$ & $\mathrm{MPa}$ & 0.025 & 0.045 & 0.006 & 0.004 & 0.164 & 0.016 & 0.044 & 0.089 & 0.049 \\
\hline \multirow[t]{2}{*}{ Parameters } & $\sigma_{t m}$ & $\mathrm{MPa}$ & 0.001 & 0.002 & 0.000304 & 0.000231 & 0.007 & 0.001 & 0.002 & 0.004 & 0.001 \\
\hline & $E_{m}$ & $\mathrm{MPa}$ & 622.28 & 1271.19 & 547.74 & 488.43 & 1582.59 & 1037.71 & 728.7 & 1157.18 & 867.97 \\
\hline
\end{tabular}




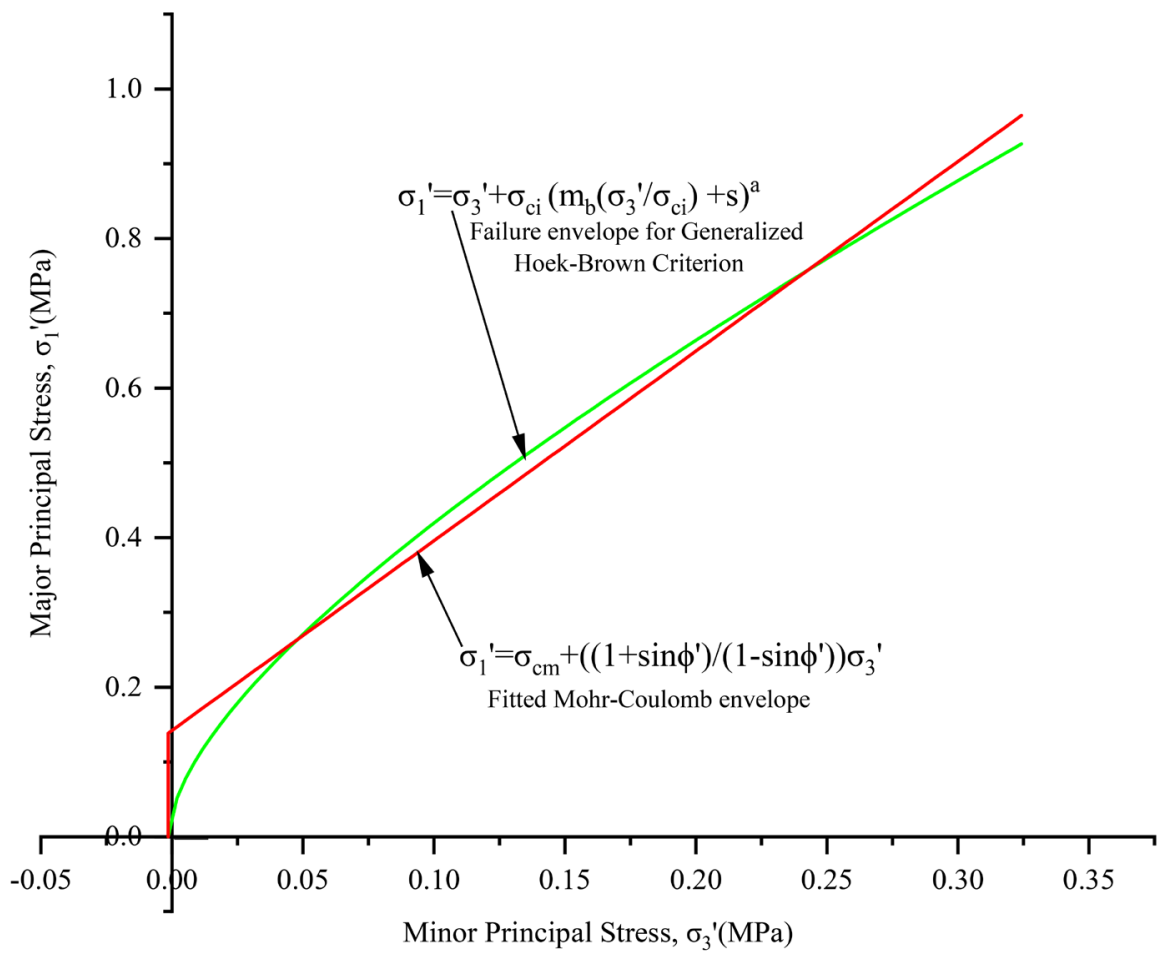

Figure 15. Relationship between major and minor principal stresses for Hoek-Brown and Mohr-Coulomb equivalent.

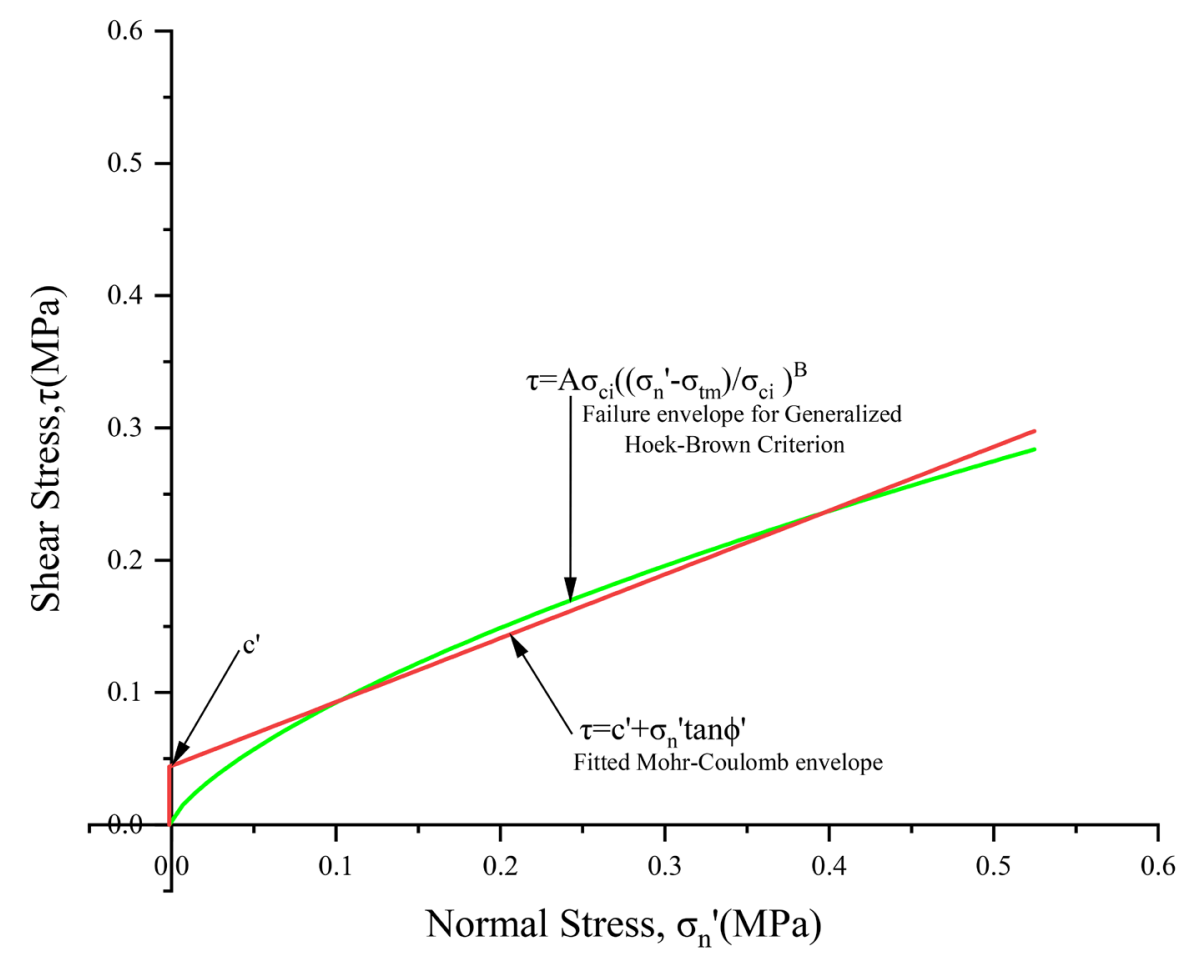

Figure 16. Relationship between normal and shear stresses for Hoek-Brown and MohrCoulomb equivalent.

biaxial stress field and it eventually stabilizes when the local strength, defined by Equation (2), is higher than the induced stresses. The shear strength envelope 
gives the rock mass' values of friction angle and cohesion.

\section{Slope Stability Considerations}

The rock mass properties have been obtained based on the state of karstification by employing the modified GSI. It is necessary to do an analysis of the stability condition of slopes constructed in this rock mass with a view of obtaining design guidelines based on the prevailing rock mass strength condition. In this regard, a deterministic parametric slope stability analysis was done for four lithological units by shear strength reduction based on Generalized Hoek-Brown Criterion. The finite element software Phase 2 was used in the analysis. GSI values of 12, $17,22 \& 27$ were selected to represent the rock mass. The slope height was varied from $5 \mathrm{~m}$ to $35 \mathrm{~m}$ while slope angle was varied from 300 to 900 . This was guided by the generally low altitude of the area under study ( $0-33 \mathrm{~m}$ above sea level) and the slope angles in the quarry. For the quarry environment, slope heights of up to $20 \mathrm{~m}$ are achieved since mining cannot be done below sea level.

Following the slope stability analysis, the graphs of Strength Reduction Factor against Slope Angle in Figures 17-20 were obtained. At the GSI value of 12 (Figure 17), slopes in this rock mass are stable at angles below 450 for $5 \mathrm{~m}$ height and below 350 for $10 \mathrm{~m}$. At GSI of 17 (Figure 18), the rock mass can accommodate

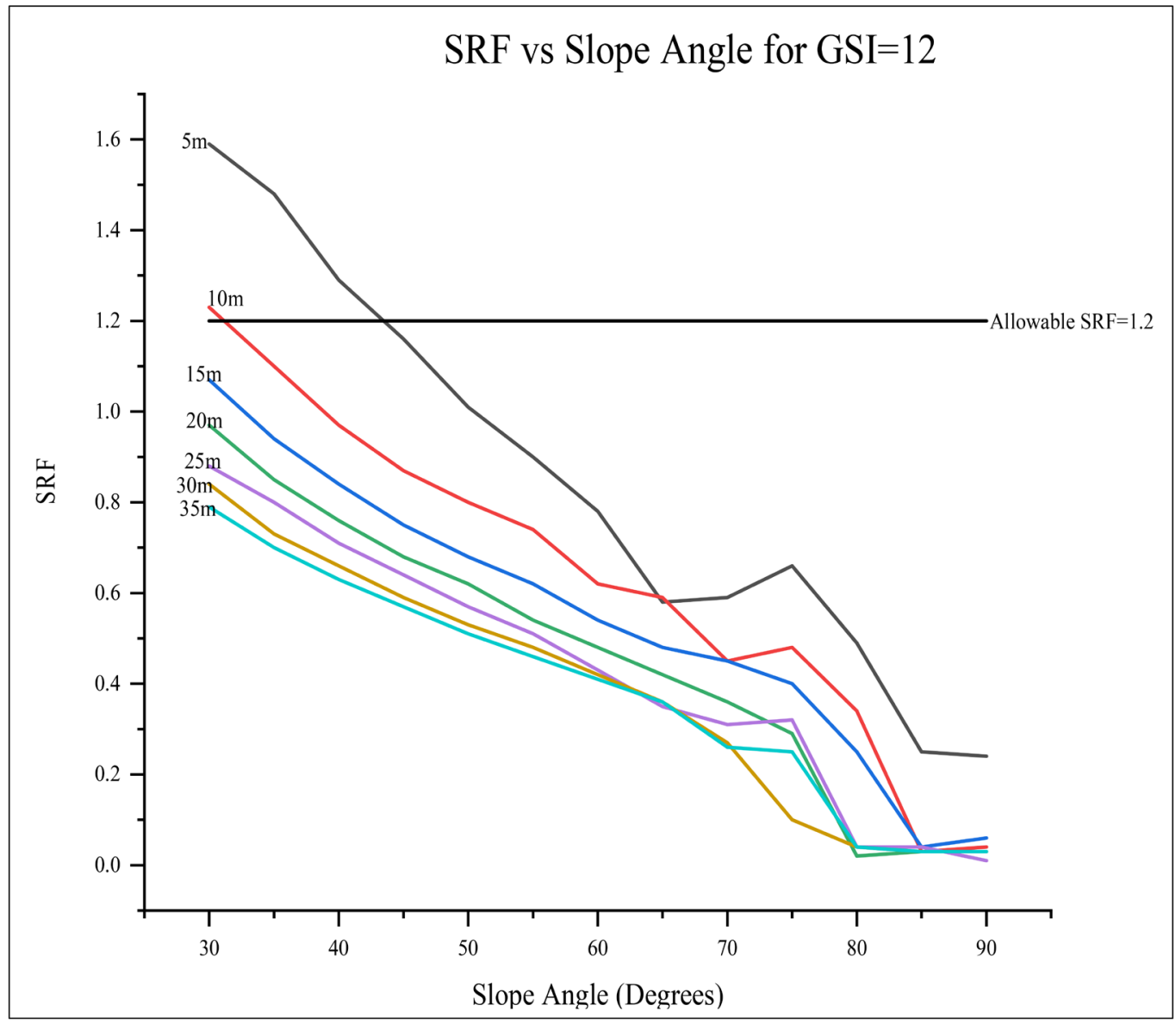

Figure 17. Plot of Strength reduction Factor vs Slope Angle for GSI = 12 . 


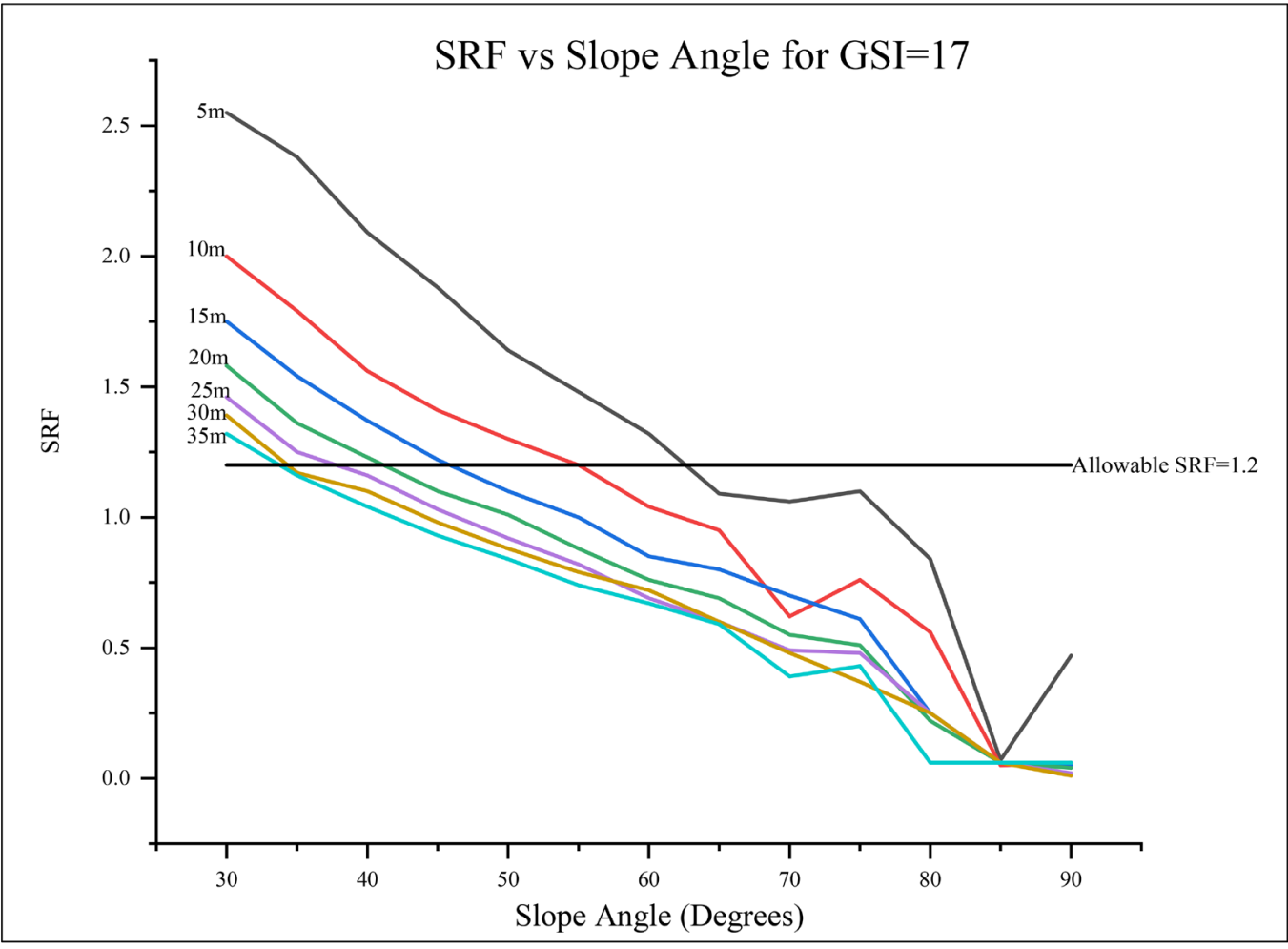

Figure 18. Plot of Strength reduction Factor vs Slope Angle for GSI = 17 .

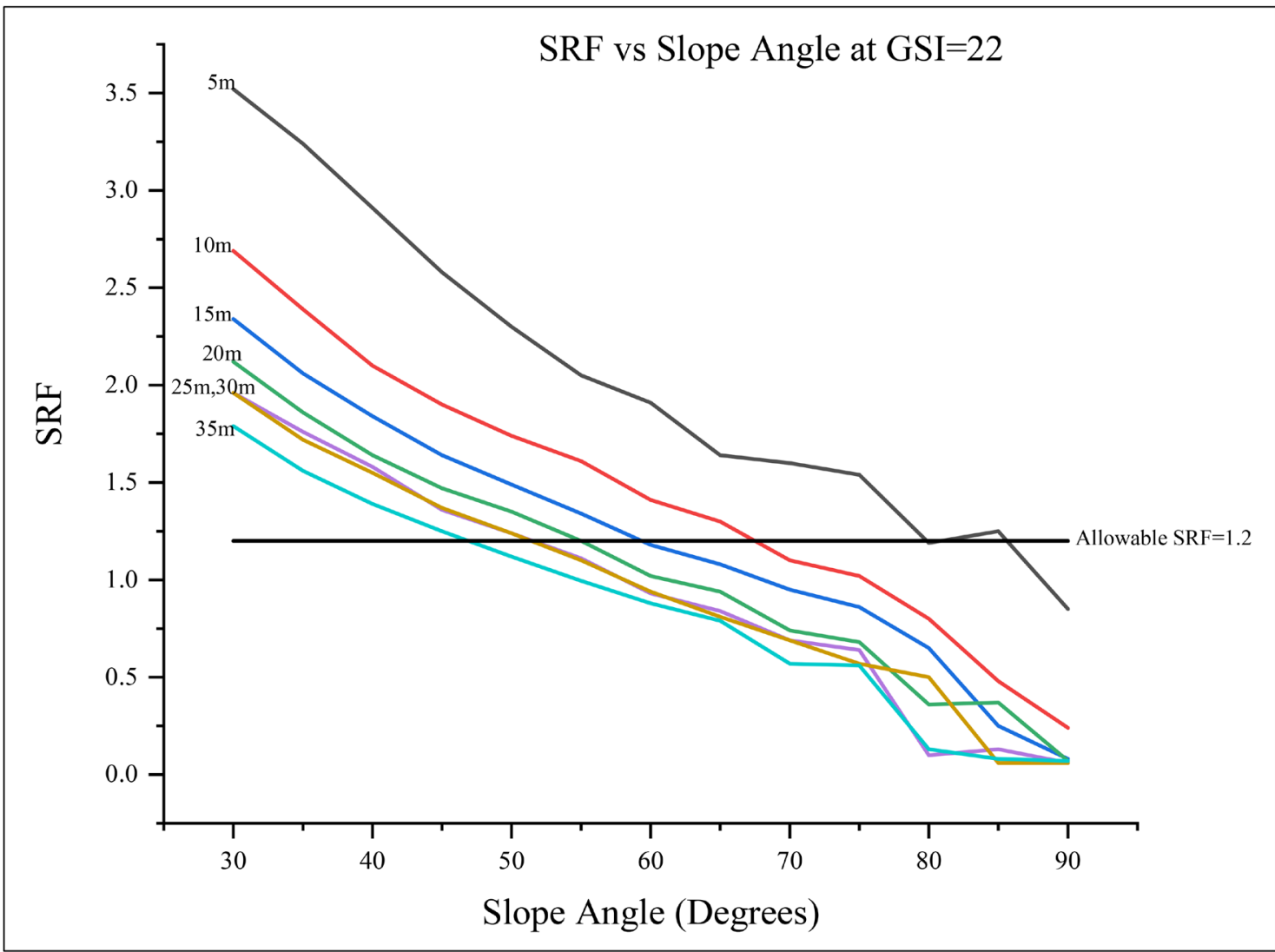

Figure 19. Plot of Strength reduction Factor vs Slope Angle for GSI $=22$. 


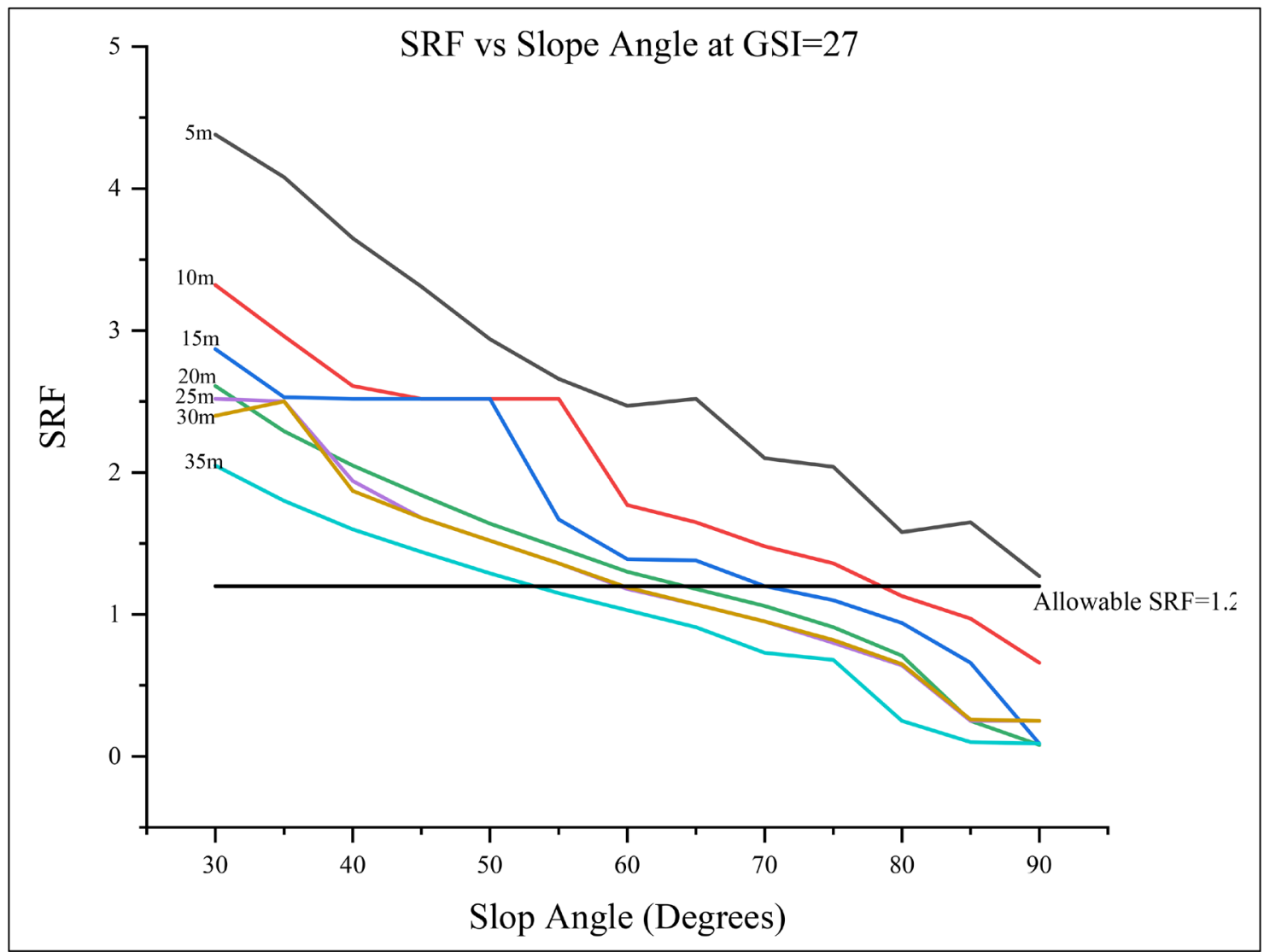

Figure 20. Plot of Strength reduction Factor vs Slope Angle for GSI $=27$.

higher slope heights and steeper angles, 650 for $5 \mathrm{~m}$ and 350 for $35 \mathrm{~m}$ height. When the GSI is at 22 (Figure 19), steep slopes of 800 and 700 are sustainable for $5 \mathrm{~m}$ and $10 \mathrm{~m}$ respectively. At $35 \mathrm{~m}$, below 450 is safe. At GSI of 27, $5 \mathrm{~m}$ is stable all through and up to 550 overall slope angle is sustainable for $35 \mathrm{~m}$ slope height. These graphs make a useful design guide especially for the overall slope angles of slopes engineered in this type of rock mass.

\section{Discussion}

The rock mass is made up of high carbonate rock of reef origin. The rock mass is porous with karst formations well developed. Structural features are not well developed so the main defects are dissolution fissures. Thin laminations are also observed in some locations. Empirical analysis based on Hoek-Brown criterion in conjunction with GSI is one of the most commonly used methods in determining rock mass properties. The GSI depends on the degree of development of the rock mass structure and features such as joints and rock fracture. The carbonate rock mass structure of reef origin under consideration in this study is not well developed and so the conventional GSI does not represent the rock mass well.

A modified GSI classification system that considers the rock porosity is employed in characterizing the rock mass. The rock mass is therefore characterized 
based on blockiness and the Uniaxial Compressive Strength of intact rock. The classification system would place a rock mass in a class and a subclass depending on the value of porosity. The aim of this work, however, was to have a GSI value that incorporates the rock porosity thus quantifying the relationship between decreasing GSI with increasing porosity. GSI value reduces with increasing porosity because regions of high porosity experience more weathering especially by water seepage and the fissures left are sometimes filled with soil especially near the surface thus weakening the rock mass even further. Rock slope design therefore needs to give serious consideration to the impacts of weathering as a result of rock porosity which has a degrading effect on the intact rock and consequently the rock mass [22].

From the characterization of eight lithological units, a logarithmic relationship was developed from the graph of GSI versus rock porosity such that the field GSI value is modified by a natural log of the value of porosity in order to incorporate the strength reduction effects. The obtained GSI value and laboratory rock properties were used to calculate the rock mass properties from RocLab software. Rock mass strength is way lower than intact rock strength and is attributed to the presence of solution fissures and thin laminations which greatly reduce the blockiness of the rock mass structure. This is consistent with results presented by Hoek and Brown [14] where for weak rocks of GSI values below 30, the strength ratio between intact rock and rock mass is much bigger than the case of medium strength and high strength rock masses. Using the mean of the rock mass property values, the failure criterion is evaluated. The principal stresses plot ( $\sigma_{1}$ vs $\sigma_{3}$ ) shows that the rock mass is only stable under very low induced stresses, below $1 \mathrm{MPa}$. The shear strength plot ( $\tau$ vs $\sigma_{n}$ ) which gives the cohesion of the rock mass as about $0.045 \mathrm{MPa}$ also shows a failure envelope encompassing very low stress values.

Slope stability analysis done for the rock mass at different GSI values indicate that slope design in this rock mass should take into consideration the rock mass strength as a design parameter besides the slope height and slope angles. Based on allowable SRF of 1.2 for open pit slopes, the plots of SRF against Slope Angle for various slope heights and various GSI values serve as a good guide for slope design in this type of rock mass.

\section{Conclusions}

Rock porosity is an important intrinsic structural feature that has an influence on rock mass strength as it directly points to the state of karstification in the rock mass. The modified GSI method which considers the state of karstification besides the intact rock strength and blockiness offers a solution to characterizing weak porous carbonate rock masses where structural features such as discontinuities are not the main controlling factors of rock mass strength.

The GSI of the rock mass reduces with increasing porosity, with a characteristic natural logarithmic relationship. This strength reduction effect of rock mass 
porosity is accounted for by the proposed empirical equation which yields the modified GSI. The equation eliminates the mental hassle of judging by how much to modify the GSI in order to take care of the strength reduction effects of rock porosity. The equation is applicable to both foliated/bedded and non-foliated carbonate rock masses.

The modified GSI ( $\mathrm{GSI}_{\mathrm{m}}$ ) has been used in determining the strength properties of the rock mass in Vipingo coral limestone quarry. The rock mass is categorized as weak, the strength being much lower than intact rock strength. A deterministic parametric slope stability analysis has been conducted for Vipingo quarry based on Generalized Hoek-Brown criterion. The graphs plotted of safety factor against slope angle for various rock mass strength conditions and slope angles make a good design guide for slopes engineered on such weak carbonate rock masses. Stability of slopes in this rock mass is sensitive to the slope angle, slope height and rock mass strength.

This work focused on rock porosity as a parameter of classifying the rock mass based on state of karstification. The carbonate rock mass however has voids that further compromise the integrity of the rock mass. Further research work on characterization of this type of rock mass needs to look into considering the presence and development of voids in the rock mass structure. A probable addition to the GSI charts could be in relation to the dimensions of the voids as well as interactions with larger caverns.

\section{Acknowledgements}

This research work is done under JICA Scholarship. Special regards to Vipingo quarry management for granting access to the quarry for data collection and also availing other relevant information. Special thanks to GeoIssa Laboratory in Nairobi for offering to assist with the laboratory tests.

\section{Conflicts of Interest}

The authors declare no conflicts of interest regarding the publication of this paper.

\section{References}

[1] Hoek, E., Wood, D. and Shah, S. (1992) A Modified Hoek-Brown Failure Criterion for Jointed Rock Masses. Rock Characterization: ISRM Symposium, Eurock'92, Chester, 14-17 September 1992, 209-214.

[2] Sonmez, H. and Ulusay, R. (2002) A Discussion on the Hoek-Brown Failure Criterion and Suggested Modifications to the Criterion Verified by Slope Stability Case Studies. Yerbilimleri, 26, 77-99.

[3] Hoek, E. (1994) Strength of Rock and Rock Masse.

[4] Hoek, E., Marinos, P. and Benissi, M. (1998) Applicability of the Geological Strength Index (GSI) Classification for Very Weak and Sheared Rock Masses. The Case of the Athens Schist Formation. Bulletin of Engineering Geology and the Environment, 57, 151-160. https://doi.org/10.1007/s100640050031 
[5] Sonmez, H. and Ulusay, R. (1999) Modifications to the Geological Strength Index (GSI) and Their Applicability to Stability of Slopes. International Journal of Rock Mechanics and Mining Sciences, 36, 743-760.

https://doi.org/10.1016/S0148-9062(99)00043-1

[6] Marinos, P. and Hoek, E. (2000) GSI: A Geologically Friendly Tool for Rock Mass Strength Estimation.

[7] Cai, M., Kaiser, P.K., Uno, H., Tasaka, Y. and Minami, M. (2004) Estimation of Rock Mass Deformation Modulus and Strength of Jointed Hard Rock Masses Using the GSI System. International Journal of Rock Mechanics and Mining Sciences, 41, 3-19. https://doi.org/10.1016/S1365-1609(03)00025-X

[8] Hoek, E., Marinos, P.G. and Marinos, V.P. (2005) Characterisation and Engineering Properties of Tectonically Undisturbed But Lithologically Varied Sedimentary Rock Masses. International Journal of Rock Mechanics and Mining Sciences, 42, 277-285. https://doi.org/10.1016/j.ijrmms.2004.09.015

[9] Hoek, E., Carter, T.G. and Diederichs, M.S. (2013) Quantification of the Geological Strength Index Chart. 47 th US Rock Mechanics/ Geomechanics Symposium 2013, Vol. 3, 1757-1764.

[10] Špago, A. and Jovanovski, M. (2019) Applicability of the Geological Strength Index (GSI) Classification for Carbonate Rock Mass. ISRM Specialized Conference and 8 th Conference of Croatian Geotechnical Society Geotechnical Challenges in Karst, Split, Croatia, 11-13 April 2019, 395-400.

[11] Hu, Z., Wen, T., Zheng, K. and Wang, Y. (2021) A Method for Determining the Mechanical Parameters of Solution Pore and Crevice Limestone Based on Porosity. Advances in Civil Engineering, 2021, Article ID: 8833370. https://doi.org/10.1155/2021/8833370

[12] Hoek, E., Carranza, C. and Corkum, B. (2002) Hoek-Brown Failure Criterion-2002 Edition. NARMS-TAC 2002: Mining and Tunnelling Innovation and Opportunity: Proceedings of the 5th North American Rock Mechanics Symposium and the 17 th Tunnelling Association of Canada Conference: NARMS-TAC 2002, Toronto, 7-10 July 2002, 267-273.

[13] Hoek, E. and Karzulovic, A. (2000) Rock Mass Properties for Surface Mines. 59-70.

[14] Hoek, E. and Brown, E.T. (1997) Practical Estimates of Rock Mass Strength. International Journal of Rock Mechanics and Mining Sciences, 34, 1165-1186. https://doi.org/10.1016/S1365-1609(97)80069-X

[15] Hoek, E. (1983) Strength of Jointed Rock Masses. Geotechnique, 33, 187-223. https://doi.org/10.1680/geot.1983.33.3.187

[16] Aydan, Ö., Akagi, T. and Kawamoto, T. (1993) The Squeezing Potential of Rocks around Tunnels; Theory and Prediction. Rock Mechanics and Rock Engineering, 26, 137-163. https://doi.org/10.1007/BF01023620

[17] Aydan, Ö., Akagi, T. and Kawamoto, T. (1996) The Squeezing Potential of Rock around Tunnels: Theory and Prediction with Examples Taken from Japan. Rock Mechanics and Rock Engineering, 29, 125-143. https://doi.org/10.1007/BF01032650

[18] Hoek, E. and Diederichs, M.S. (2006) Empirical Estimation of Rock Mass Modulus. International Journal of Rock Mechanics and Mining Sciences, 43, 203-215. https://doi.org/10.1016/j.ijrmms.2005.06.005

[19] Bell, F.G. (1992) Engineering in Rock Masses. Butterworth-Heinemann, Oxford. https://doi.org/10.1016/B978-0-7506-1965-3.50017-0

[20] ISRM (1981) Rock Characterization Testing and Monitoring. ISRM Suggested Methods. Pergamon Press, Oxford. 
[21] Martin, D. and Stacey, P. (2018) Guidelines for Open Pit Slope Design in Weak Rocks. CRC Press, Boca Raton. https://doi.org/10.1071/9781486303489

[22] Marinos, V. and Carter, T.G. (2018) Maintaining Geological Reality in Application of GSI for Design of Engineering Structures in Rock. Engineering Geology, 239, 282-297. https://doi.org/10.1016/j.enggeo.2018.03.022

\section{Nomenclature}

$\begin{array}{ll}\sigma_{1}^{\prime} & \text { major effective principal stress at failure } \\ \sigma_{3}^{\prime} & \text { minor effective principal stress at failure } \\ \sigma_{c i} & \text { intact rock uniaxial compressive strength } \\ a, s, m_{i}, m_{b} & \text { Hoek-Brown material constants } \\ \sigma_{c m} & \text { rock mass uniaxial compressive strength } \\ \sigma_{t m} & \text { rock mass tensile strength } \\ \phi_{m} & \text { rock mass friction angle } \\ c_{m} & \text { rock mass cohesion } \\ v_{m} & \text { rock mass Poisson's ratio } \\ E_{i} & \text { intact rock deformation modulus } \\ E_{m} & \text { rock mass deformation modulus } \\ D & \text { disturbance factor } \\ N & \text { porosity } \\ \tau & \text { shear stress } \\ \sigma_{n} & \text { normal stress } \\ \mathrm{GSI} & \text { modified GSI }\end{array}$

